\title{
Green Volunteerism - A new approach to achieve the United Nations' Sustainable Development Goals
}

\author{
Tan Xin Yee', Chong Chin Wei'1, Adedapo Oluwaseyi Ojo ${ }^{1}$ \\ ${ }^{1}$ Faculty of Management, Multimedia University, Cyberjaya Campus, Malaysia
}

\begin{abstract}
The Earth's climate has changed in great measure throughout history, and it significantly impacts human society, economic development, and ecological degradation. Understanding how to sustain green volunteerism among youth is an important issue to confronting today's ecological challenges, especially when they may serve as future leaders of environmental movements. In a focus group setting, 25 representatives of multi-stakeholders discussed how and why students in higher education institutions participate in green volunteering. Transcripts from the conversation were analyzed to comprehend the motives, challenges, and benefits of youth engagement in green volunteering. Findings suggested that young adults are aware of and working on climate issues. A few issues were raised as challenges and/or demotivating factors in youth engagement among green volunteerism.
\end{abstract}

Keywords: green volunteering; youth engagement; focus group study

This is an open access article under the CC-BY-NC license.

\section{INTRODUCTION}

Climate change, as a complex global issue that felt on the local scale, relates to numerous issues, including economic development, obliteration of ecosystems, governmental issues, and financial crisis. It is undeniable that human behavior and unsustainable development which failed to take environmental impacts into accounts such as deforestation, open burning, river and ocean pollution is the primary driver of these issues.

The snowballing of climate change could severely impact human society and the natural environment. The Intergovernmental Panel on Climate Change (2014) proposed such changes are unambiguous, and most of it is vastly presumably to be the results of human activities. $97 \%$ actively publishing climate-researchers agreed that human activities that emit greenhouse gases are the main causal factor (American Association for the Advancement of Science, 2009 \& Cook et al., 2016). Furthermore, small daily actions that contribute to carbon footprints profoundly, such as using single-use plastics and packaging and meat consumption, are also impacting the climate severely (Laville, 2019). The good news is: individuals are making small changes in their daily habits to

Corresponding author

Tan Xin Yee, 1191402526@student.mmu.edu.my; Chong Chin Wei, cwchong@mmu.edu.my; Adedapo Oluwaseyi Ojo, ojo.adedapo@mmu.edu.my 
mitigate climate change. For instance, people began using reusable containers and consuming a plant-based diet.

However, uptake of environmental-friendly actions needs to be increased rapidly; otherwise, individuals, society, and the planet will be severely influenced. Although the benefits climate actions bring would be incredible for society, for individuals, and for the planet, it takes time. Meanwhile, the consequences brought by climate change will continue to snowball and influence all organisms on the planet, hence, there is an urgent need to rapidly increase environmental and climate action.

As the global climate change peaks, one of the population groups that need to face the impact would be the younger generation. Today's generation of young adults is likely to be more conscious of their place within the ecological landscape. Indeed, given the youth has witnessed the worst oil spill in human history and lived through the ecological devastations caused by natural disasters like hurricane Katrina, the earthquake in Haitian, and tsunamis in Japan, some believe that this generation will be crucial in driving the environmental evolution forward. Fernandez, Thi, and Shaw (2013) purported that the awareness of climate change of today's youth is critical as they are the populace that bears the majority disaster impacts and whose well-being may be severely affected. They are the key agents for social change and are providing the energy, creative ideas, and determination to drive innovation and reform, and more efforts are needed to effectively engage them in environmental action (UN World Youth Report, 2003; Quiroz-Martinez et al., 2005). Hence, empowering today's youth to alleviate climate change impacts should be an educational priority since youth are the future citizens and decision-makers that must live with the impacts of climate change and take action on implementing solutions (Narksompong, 2015).

Youth volunteerism, with the underpinning value of reciprocity, responsibility, and participation, ensures a long-term impact by changing people's mind-sets, attitudes and actions. In 2000, Wilson described volunteering as an altruistic activity where services are provided by a person or group, without gaining social or financial benefit and looking to contribute to another person, community, or organization in his publication. Individuals will choose their goals and achieve them within the limitations of certain cultural, societal, and legal constraints (Dillon, 2014). The services provided could be religious, civil, medical, educational, environmental, etc. Similarly, Mowen \& Sujan (2005) defined volunteering as activities which often intended to enhance the wellbeing of others; and volunteers as individuals who offer help without expecting monetary rewards.

Green volunteering includes various activities such as environmental monitoring in wildlife, ecological restoration, and education. These activities involve government and nongovernment organizations (such as nature education centers, aquariums, park agencies, and local communities) and usually rely heavily on volunteer participation (Lindsay, 2006). They participate in a wide array of activities, including vegetation cutting, habitat management, removing invasive species, and fundraising. Uptake of such volunteering behaviors usually originated from the need to fulfil the personal desires of the volunteers (such as feeling needed and cultivating a sense of place) (Gooch, 2005). NGOs and community involvement are crucial in undertaking green efforts (Arumugam, 2019) and volunteers are vital to the green sector. For many environmental organizations, the volunteer workforce is fundamental to their operation (Flattery, 2020). 
The process and experience of taking part in volunteering programs could become both a goal and outcome. There are multiple benefits of volunteering (Low et al., 2007; Marta \& Pozzi, 2008; Hall et al., 2007; Ott and Dicke, 2016; Smith et al., 2010; Sahri et al., 2013). In volunteering activities, individuals from different age groups collaborate and cooperate; they acknowledge each other as resources, learn from each other and broaden their opportunities for participation. It is also a platform for people to form social networks, and hence communities are strengthened through the selflessness helping behaviors.

Young people are the next generation of citizens and national leaders that need and have to survive through global climate change impacts and commit to implementing solutions (Narksompong \& Limjikaran, 2015). Societies, therefore, need to be capable of turning the potential of their youth into action, leveraging their capabilities, skills, and creativity to envisage a sustainable future, especially for the climate change challenge. Henceforth, there is a need to study youth participation in green volunteering and its' subsequent benefits, and insights could be gained in creating endless possibilities of engaging youth in green volunteering.

This study aimed to provide insights into curriculum and learning support that would be required to develop graduates to a high level of personal well-being and enable them to contribute to the harmony and betterment of the society and nation community. The researchers were also looking to extend the current understanding of youth engagement in environmental volunteer actions by investigating the relationship between motivating factors and green volunteering participation among higher education institutions (HEI) students.

\section{LITERATURE REVIEW}

Countless benefits could be obtained via volunteering directly and indirectly (Squirrell, 2009, Holdsworth, 2010), but the volunteering rate is decreasing, particularly within the youth population, drifting to a 10-year low where the youth (aged between 20-24 years old) is having the lowest volunteering rate at 18.4\% (Bureau of Labor Statistics, 2016). Cramer et al. reported only $4 \%$ of college graduates volunteer each year (2006).

Survey-based data sets indicated that young people usually cited lack of time, funding, and opportunity as the reason for not joining volunteering programs (Brewis et al., 2010). Similarly, NCCPE also reported that students need to attend to paid work, and the costs incurred from unpaid work, like travelling, might be the challenges that discourage volunteerism (Squirrell, 2009). However, such a survey has not been conducted in the environmental context. Henceforth the influence of accessibility as in time availability, financial cost, commitment, capacity, transportation, and opportunity on green volunteering participation needs to be studied.

Previous researches have focused on studying the relationship between different motivating factors and volunteering participation (Benabou and Tirole, 2006; Carpenter \& Myers, 2007). It was suggested by a study in England that university students quoted both altruistic and instrumental factors as their reason to volunteer (Holdsworth, 2010). The most important reasons for volunteering were as follows: to help someone in their community, to develop new skills, to respond to their needs or skills, and to gain experiences that benefit their future career. In 2019, a study was conducted investigating the motivations and experiences of volunteers and patients in mental health befriending using the thematic analysis technique (Cassidy et al.). Similarly, Kelly (2014) explored the motivating factor and challenges associated with volunteering among 
university students, while Govender (2014) studied the experiences of volunteers within the counselling context, both via quantitative study. It was shown that qualitative studies, particularly the thematic analysis technique, aid the understanding of volunteers' experiences in depth (Dein \& Abbas, 2005; MacNeela, 2008, Rovers et al., 2016).

In the environmental context, volunteerism has been studied as a pro-environment behavior. Researchers described volunteer work in a green context as a conscious decision of the actor indicating his/her desire for further involvement as an active citizen in a collective effort towards a mutual goal which might be the quick fix of ecological complications (Liarakou et al., 2011). Findings from Tessier et al. (2006) presented that the youth were less likely to report engagement in green volunteering, although they have expressed an interest in ecology and the environment. Hall et al. (2007) studied volunteerism among Canadian adolescence aged and reported a lower likeliness of volunteer engagement in the environmental context. However, researches did indicate the interests of youth being engaged in green volunteering (Volunteer Canada, 2001 \& Lindsay, 2006). A study indicated that Canadian youth aged between 15-24 are interested in engaging in volunteering for organizations that support environmental issues (Hientz et al. 2010).

However, few kinds of research have delved into the intersection of green volunteering and youth volunteering, although growing (Puckett, 2015). Marta and Pozzi have criticized the scarcity of volunteering-related literature related to adolescences and young adults in 2008; similarly, Hamzah (2015) suggested that studies to understand youth participation are necessary. Studies that explore the significance of youth engagement in volunteering activities could come together with studies on the advantages of interacting with the environment and contribute understandings in youth engagement in green volunteering, which could result in limitless opportunity (Puckett, 2015). In 2007, Bruyere and Rappe highlighted the significance of green volunteering where the natural environment indeed benefits from the volunteers' work. Environmental organizations depend greatly on unpaid volunteers on sustaining and saving the endangered natural environment. However, the reason for volunteering for such a cause has remained unrecognized. The motivating factors include altruistic ones and personal interest and/or development (Bruyere \& Rappe, 2007).

To date, the majority of the studies on volunteering focused on empowering youth volunteerism and motivating factors (Mardiyyah et al., 2013), studying the challenges in voluntary work (Kauthar et al., 2013), examining the factors that influence people to volunteer (Suandi et al. 2011), etc. Researches associated with understanding youth participation in volunteering activities remains lacking (Hamzah et al., 2015). Researches suggested that volunteer organizations might be lacking the internal support to get young people engaged and that negative impressions of young people's capabilities as volunteers added a huge challenge to promoting green volunteerism within youth (Volunteer Canada, 2001, Tessier et al., 2006, Shannon et al., 2009 \& Moffatt, 2011). It is crucial to captivate and preserve the youth as volunteers, especially in offering their services to protect the environment (Hamzah et al., 2015). A supportive environment is required to encourage young people to strive for participation in volunteering, which will provide them with an opportunity to support their home, local community, and environment besides improving their capability and employability as well as the improvement of human capital and social within the nation. 
It is commonly agreed that encouraging youth to volunteer in serving the community and individual will benefit society (Hamzah et al., 2015). Throughout history, volunteering is a contribution to society in one form or another without monetary reimbursement. Studies suggested that the majority of youths participate actively in volunteering activities to satisfy their own needs while helping others in their community (Gage and Thapa, 2011). To date, the majority of the studies on volunteering in Malaysia focused on empowering youth volunteerism and motivating factors (Mardiyyah et al. 2013), studying the challenges in voluntary work (Kauthar et al. 2013), examining the factors that influence people to volunteer (Suandi et al. 2011), etc. This study will focus on youth participation and the reasons why they become involved in a volunteering program.

Extensive researches were carried out on the rationale of people volunteering, but the focus given to green volunteering has been relatively less (Gooch, 2005, Bruyere \& Rappe, 2007; Measham \& Barnett, 2008; \& Puckett, 2015). Past studies suggested that green volunteering differs from general volunteering; however, a common viewpoint to assess the motivation of environmental volunteers is yet to be established (Puckett, 2015). Hence, there's a need to explore an applicable inventory and examine it across nationality, age groups, ethical background, and other variables.

Additionally, limited studies were done in studying Malaysian youth's awareness and attitudes towards volunteering, especially green volunteering (Narksompong \& Limjikaran, 2015). Hence, there's a need the understanding, and possibility in accessing, the motivation of green volunteers. Also, the contribution of youth was relatively absent from discussions of green volunteering. Efforts need to be made in emphasizing youth as the study focus to understand youth participation in green volunteering, not to suggest that they are less than the adult, but to make space for their voices in green volunteering (Puckett, 2015).

Today's youth (aged from 15 to 24) accounts for 17\% of the Earth's population, or 1.2 billion individuals, with the majority living (87\%) in developing nations. Therefore, educating them about climate change issues should be a prior task in alleviating climate changes since they are the next generation of citizens and national leaders that have to survive through climate change impacts and commit to implementing solutions (Narksompong \& Limjikaran, 2015). The term 'youth' is a socially constructed concept that is commonly presumed as the transition period between childhood and adulthood. The United Nations limited youth to individuals aged between 15 to 24 years old, and there was about 1.2 million youth globally, which accounts for one-sixth of the population worldwide. Among the young adults, those who pursue tertiary education in a higher education institute are most likely to contribute to mitigating global climate change. Higher education, sometimes also known as tertiary education, post-secondary education, or third-level education, is the changing stage in life where most of the youth would experience. It is a noncompulsory final stage of formal learning that occurs after the fulfilment of secondary education. The scholars of these higher education institutions have great potential in leading an innovative change in the country's future.

Having the literature in mind, this study explored the intersection of "youth", "volunteering," and "environment" in the Malaysian context. Volunteering attitudes, experiences, activities, and their motivating factors will be investigated in this research, focusing on the population of Malaysian youth in the environment field. In this study, volunteering activities were studied from multiple perspectives via focus group discussions where multi-stakeholders 
discussed the status of volunteerism among youth. The data collected was then analyzed using the thematic analysis technique.

\section{RESEARCH METHOD}

To gain insights into the current state of youth volunteerism, particularly in the environmental setting, focus group discussions were held among related personnel, including representatives from government, volunteering organizations, private sectors, student associations, and student volunteers. Focus group discussion is a frequently used qualitative approach to gain an in-depth understanding of social issues (Nyumba et al., 2018). A purposely selected group of individuals was assembled to discuss a specific topic, aiming to retrieve participants' perceptions, opinions, and attitudes toward the youth volunteering phenomenon.

To address the gaps in current literature, this research focused on identifying themes within the participant's understanding, where this could provide the researcher with scope for further investigation of the subject in question. Hence, the most appropriate method of analysis would be the thematic analysis. In this study, Braun and Clarke's publication in 2006, which defined and described a sequence of phases that researchers must go through to conduct a thematic analysis, was referenced while analyzing the collected information.

A total of 28 participants were invited from multi-stakeholders, including representatives from the Ministry of Education, non-governmental organizations specialized in green volunteering, private sectors, student volunteers, and student association representatives from different HEIs. They form into groups of 4 to 5 , commenting on the importance of youth volunteerism in achieving sustainable development and discussing how green volunteerism could be effectively promoted and sustained among HEI students. Participants discussed four topics, including (1) the current state of youth volunteerism, (2) the current state of green volunteerism among youth, (3) the factors influencing youth's participation in volunteering activities, and (4) the challenges and strategies regarding the promotion of green volunteerism among youth. A few measures were applied to assure the validity and reliability of the study. The question list used during the focus group discussion was drafted based on a literature review and reviewed by experts in the related field beforehand. A pilot interview was conducted with 2 representatives from the sampling frame and the discussions were reviewed so the most appropriate data could be retrieved. All discussions were had, recorded, and analyzed in English, and the sessions each lasted about 50 minutes.

\section{FINDINGS AND DISCUSSION} Findings

Analysis of the transcripts revealed five themes, namely (1) volunteering is a thing among youth, (2) green volunteering is pending expansion among youth, (3) youth volunteer for a certain outcome, (4) peer is a double-edged sword, and (5) youth are occupied by other commitments. For clarity, the number of units relating to each category is presented in brackets following categories of each theme are presented.

1. Volunteering is a thing among the youth

Participants discussed the current state of volunteerism among Malaysian youth and the observed attitudes towards volunteerism. Perhaps unsurprisingly, all the participants confirmed 
that, in general, there is an observed increasing trend of participation in volunteering activities (28): 'We do have more student volunteers now.' Observations suggested that there are a few patterns in youth's attitude towards volunteerism (11) where youth are interested in volunteering (8).

'I think there are two types of attitudes about volunteerism, first is that they are very interested in volunteering, but some of them could not find a pathway to devote themselves as a volunteer; second is that they have no time and/or interest in volunteering,' according to participant $\mathrm{A}$, a representative from a non-governmental organization (NGO).

'To my volunteer friends and I, we think volunteering is fun and a good way to spend our time; however, there are also people who think it's a waste of time,' said participant B, a student volunteer.

Student volunteer participant E indicated 'student volunteers are the main source of our manpower; however, they often participate in the form of 'touch-and-go. They only participate in volunteering activities for a minimum duration that requires them to complete the compulsory community service subject, and then they don't come anymore. Some do stay and prolong their volunteering services, but a lot of them don't.'

'Youth could be interested in volunteering, but they just don't have the chance to get to know the programs, or they don't know they need to do it. I believe awareness could be increased by having sharing sessions that experienced volunteers share their gains and thoughts about volunteering. We often observe high registration and participation after such sharing sessions,' government representative, participant $\mathrm{C}$ suggested.

\section{Green volunteering is pending expansion among youth}

Few participants suggested that green volunteering is growing rapidly (9), while others thought green volunteering is not widely acted upon yet (13). Volunteering organizations often use green volunteering activities as a starting point of getting youth engaged (4).

Student association representative participant D suggested that 'we can see that green volunteering activities in our undergraduates are slowly increasing. They are scattered everywhere, some in MMU, some in UTAR, maybe only a few of them in each institute, but the trend is slowly picking up.'

'We often use green volunteering activities such as recycling programs and beach cleaning activities as an attractive method to bring in new volunteers, because these activities or programs are more accessible, more interesting and friendlier, said student volunteer participant $\mathrm{E}$.

'Youngsters are aware of the environmental issues and they are very powerful in changing our future, they have endless potential, but they need to be educated on what and how can they help the planet. For example, many of them know that we need to do recycling, but they don't know what can be recycled and what cannot, they still need guidance and information,' government representative participant $C$ suggested.

NGO representative participant A expressed, 'it's hard to get a large group of students to visit orphanage or old folk's homes that need help, but we can guide them to clean a hill and process recyclables.' 


\section{Youth volunteer for a certain outcome}

Participants suggested that youth volunteer for certain tangible or intangible outcomes (23), including academic progress (20), social connections (12), skill-learning (14), etc.

'To be honest, I started volunteering because I needed to complete the compulsory community service subject, but after a while, I found it was fun,' said student volunteer participant E.

'I believe there are many good reasons to volunteer, like learning soft-skills such as planning events, cooperation and communication. Students will receive certificates from us, which they can put in their resume. Some of them even get a job offer from the organization they work with.' According to participant A, an NGO representative.

'I was once interviewed for my internship. I wrote my volunteering experiences on my resume and received good feedback, I think volunteering looks good on my resume.' said participant B, a student volunteer.

'When we promote volunteering activities on campus, the first thing students ask is - is this activity counted in the compulsory community service subject and the second is will they receive certification,' student association representative participant D suggested.

\section{Peer is a double-edged sword}

Social connection is one of the outcomes youth are looking for in volunteering (12), and it works two ways. Most of the Time, youth participate in volunteering programs to try new things with their friends (9) or because they have friends that influenced them (7). Other times, youth who are interested in volunteering join the programs to seek peers that share a common interest (4).

'Peer is a factor in motivating volunteerism too, it can be good or bad. Some students volunteer their time because they want to spend time with their friends in meaningful activities, or simply because all the friends are joining and they don't want to be left out. It can also be another way around, students do not volunteer as they rather spend time with their friends on other activities, or they don't want to appear odd especially volunteering is not a trend in their circle,' government representative participant $C$ suggested.

'Peer pressure was one of the biggest challenges when I try to promote volunteering activities. To university students, friends are very important. We care a lot about what our friends think of us. When I tell my friends about my volunteering experiences, I would be concerned. Is spending my weekends at an old folk's home going to make me seems weird? If I invite my friends to clean the beach together, will they agree or think it's a waste of time? It might sound naïve, but young people care about others' impression on us a lot, and this reduces the exposure of volunteerism,' said student volunteer, participant $\mathrm{E}$.

\section{Youth are occupied by other commitments}

The final theme highlights the challenges that stop or discourage youth from participating in volunteering activities. Many thought time management is an issue (21) and that today's youth have too many other commitments (24) such as study (13), self-care (7), work (8), and entertainment (11).

Student volunteer participant B stated 'Time is a big issue, after allocating time for study and self-care, there's not much time left. We often save it for entertainment instead of volunteering. 
Another thing is interest, if we have a strong interest and determination in volunteering, we will make time for it. For example, my friends and I, pay more attention during class to enhance efficiency in academic, and we spend less time on entertainment so that we can make time to participate in volunteering activities.'

'They have too many things to do with only 24 hours a day. They need to study, hang out with their friends, have fun with life, rest... and not to mention, a lot of them work a part-time job to earn pocket money,' said NGO representative participant A.

'Half of my day is typically spent on self-care and rest. Then study takes a quarter of the day off, and I have less than 6 hours for social, family and volunteering,' said student volunteer, participant E.

\section{Discussions}

1. Comprehensive understanding

The results detailed above featured some significant discoveries as to how youth comprehend climate change in terms of portions of its consequences and necessary actions to mitigate it. It was particularly certain that awareness concerning climate change, often imparted in education, is high in the current youth populace. However, it appears equally evident that this awareness, in many cases, does not transfer to pro-environmental behavior. Further investigations will allow us to explore the potential reasons behind the awareness-behavior gap.

Results of this study have provided support to the idea of qualitative researches, applying the thematic analysis technique, in particular, aid the understanding of volunteers' experiences in depth (Dein \& Abbas, 2005; MacNeela, 2008, Rovers et al., 2016). It has also supported the findings where the youth do have an interest in saving the environment, although their participation in such field was low (Tessier et al., 2006, Hall et al., 2007, Volunteer Canada, 2001 \& Lindsay, 2006).

As reported by Brewis et al. in 2010, the youth usually cite lack of time, funding, and opportunity as the reason for not volunteering. Also, it was reported that students need to attend to paid work, and the costs incurred from unpaid work such as travelling might be the challenges that discourage participation in volunteering activities (Squirrell, 2009). These were also shown in the current study where the youth are occupied by other priorities such as study and self-care.

In Holdsworth (2010) report, it was mentioned that the most important motives of volunteering include: to help someone, to develop new skills, to respond to their own needs or skills, and to gain experiences that benefit their future career. It was found in the participants' responses where the current youth often volunteer for certain tangible or intangible outcomes.

There is not a wealth of prior research in this domain, and thus the thematic analysis technique was chosen to analyze the data. The method proved to be particularly useful in generating these exploratory data that are discussed herein as related to previous findings. It is clear from our data that green volunteerism among youth in Malaysia requires further attention.

Further research should investigate factors affecting green volunteering participation among youth, and it does not only constitute the cardinal elements of civil society; but also, the crucial dimensions in promoting both individual and collective competence of the nation. Hence, gaining insights into how to popularize green volunteerism among youth is a critical issue in mitigating the ecological crisis the Earth is facing today, particularly when these young people can act as leaders in the future environmental movement. 


\section{Implications for future}

Findings of this research aided in ascertaining the current state of green volunteerism in Malaysian youth, identifying the common factors that encourage the participation of HEI students, to identify the "levers and barriers" of volunteerism that can influence their interest in green volunteering. This constitutes not only the fundamental dimensions of civil society but also critical aspects of the promotion of both self and collective efficacy. Thus, understanding how to sustain green volunteerism among youth will certainly be an important issue when confronting the ecological challenges of today, especially because these young people will serve as future leaders of the environmental movement.

\section{CONCLUSION \& FURTHER RESEARCH}

Compiling the insights gained, it could be said that, in general, Malaysian youth has a relatively high awareness of volunteering programs; however, the participation rate and duration could be improved. Green volunteerism appears favorable and accessible to university students. Participants agreed that Malaysian youth are essential and potential in mitigating the climate issue. However, they are not equipped with the necessary knowledge. It was suggested that time and opportunity are usually the barriers, while social and rewards are the common motivators for youth to volunteer.

Similar researches are recommended to be carried out in the future, not only in green volunteering and/or youth volunteering but also in other contexts like sports volunteering and disaster relief actions. The investigation could also be furthered by validating the suggested factors in the field study, for example, sending out a questionnaire to study the challenges faced by HEI students in terms of engaging in green volunteering.

\section{ACKNOWLEDGEMENT}

This research was funded by the Fundamental Research Grant Scheme [FRGS/1/2019/SSI09/MMU/02/2] Ministry of Higher Education Malaysia.

\section{REFERENCES}

American Association for the Advancement of Science (AAAS). "AAAS Reaffirms Statements on Climate Change and Integrity." American Association for the Advancement of Science, 2009, www.aaas.org/news/aaas-reaffirms-statements-climate-change-and-integrity. Accessed 11 Nov. 2020.

Arumugam, T. “'Selangor, a Role Model for Green Initiatives' | New Straits Times." NST Online, 2 Nov. 2019, www.nst.com.my/news/nation/2019/11/535083/selangor-role-model-greeninitiatives. Accessed 11 Nov. 2020.

Bénabou, R, and J Tirole. "Incentives and Prosocial Behavior." SSRN Electronic Journal, 2004, 10.2139/ssrn.639043. Accessed 12 Apr. 2019.

Braun, V, and V Clarke. "Using Thematic Analysis in Psychology." Qualitative Research in $\begin{array}{llllll}\text { Psychology, } & \text { vol. } 3, \quad \text { no. 2006, } 2 \text { pp. }\end{array}$ www.tandfonline.com/doi/abs/10.1191/1478088706qp063oa.

Brewis, G, et al. Valuing Volunteer Management Skills. London: Institute for Volunteering Research., 2010. 
Bruyere, B, and S Rappe. "Identifying the Motivations of Environmental Volunteers." Journal of Environmental Planning and Management, vol. 50, no. 4, July 2007, pp. 503-516, $10.1080 / 09640560701402034$.

Bureau of Labor Statistics. "Volunteering in the United States - 2015." US Bureau of Labor Statistics, 2016, www.bls.gov/news.release/pdf/volun.pdf. Accessed 11 Nov. 2020.

Carpenter, J, and C K Myers. "Why Volunteer? Evidence on the Role of Altruism, Image, and Incentives." Journal of Public Economics, vol. 94, no. 11-12, Dec. 2010, pp. 911-920, 10.1016/j.jpubeco.2010.07.007. Accessed 13 Apr. 2020.

Cassidy, M, et al. "Motivations and Experiences of Volunteers and Patients in Mental Health Befriending: A Thematic Analysis." BMC Psychiatry, vol. 19, no. 1, 17 Apr. 2019, 10.1186/s12888019-2102-y. Accessed 11 Nov. 2020.

Cook, J, et al. "Consensus on Consensus: A Synthesis of Consensus Estimates on HumanCaused Global Warming." Environmental Research Letters, vol. 11, no. 4, 1 Apr. 2016, p. 048002, iopscience.iop.org/article/10.1088/1748-9326/11/4/048002,

$10.1088 / 1748-$ 9326/11/4/048002. Accessed 11 Nov. 2020.

Cramer, K, et al. College Students Helping America. Corporation for National and Community Service, Oct. 2006.

Dein, S, and S Q Abbas. "The Stresses of Volunteering in a Hospice: A Qualitative Study." Palliative Medicine, vol. 19, no. 1, Jan. 2005, pp. 58-64, 10.1191/0269216305pm969oa. Accessed 11 Nov. 2020.

Dillon, M. Introduction to Sociological Theory: Theorists, Concepts, and Their Applicability to the Twenty-First Century. Chichester, West Sussex, Uk, John Wiley \& Sons, 2014.

Fernandez, G, et al. "Climate Change Education: Recent Trends and Future Prospects." Disaster Risk Reduction, 2014, pp. 53-74, 10.1007/978-4-431-55090-7_4. Accessed 11 Nov. 2020.

Flattery, L. "Green Volunteerism in the UK - We Need More Asap." Medium, 15 Jan. 2020, medium.com/@transitionlab.earth/green-volunteerism-in-the-uk-we-need-more-asap92b58604bb0b. Accessed 11 Nov. 2020.

Gage, Richard L., and Brijesh Thapa. "Volunteer Motivations and Constraints Among College Students." Nonprofit and Voluntary Sector Quarterly, vol. 41, no. 3, June 2011, pp. 405-430, 10.1177/0899764011406738.

Gooch, M. "Voices of the Volunteers: An Exploration of the Experiences of Catchment Volunteers in Coastal Queensland, Australia." Local environment, vol. 10, no. 1, Feb. 2005, pp. 5-19, 10.1080/1354983042000309289. Accessed 1 Mar. 2020.

Govender, R. The Making of a Volunteer: A Qualitative Study. 2014, uir.unisa.ac.za/bitstream/handle/10500/18797/dissertation_Govender_R.pdf?sequence=1\&isAll owed=y. Accessed 11 Nov. 2020.

Hall, M, et al. "Caring Canadians, Involved Canadians. Highlights from the 2007 Survey of Giving, Volunteering, and Participating." Imagine Canada, 2007, www.imaginecanada.ca/files/www/en/giving/csgvp_highlights_2007.pdf. Accessed 11 Nov. 2020.

Hientz, M, et al. "Bridging the Gap: Enriching the Volunteer Experience to Build a Better Future for Our Communities. Summary of Findings of a Pan Canadian Research Study." 2010.

Holdsworth, C. Student Volunteers: A National Profile. London: Volunteering England/Institute of Volunteering Research., 2010. 
Intergovernmental Panel on Climate Change (IPCC). "Climate Change Fifth Synthesis Report: Summary for Policymakers Chapter." IPCC — Intergovernmental Panel on Climate Change, 2014, www.ipcc.ch/site/assets/uploads/2018/02/AR5_SYR_FINAL_SPM.pdf. Accessed 11 Nov. 2020.

Kamaludin, K M, et al. "Challenges in Volunteering from Cancer Care Volunteers Perspectives.” Asian Pacific Journal of Cancer Prevention, vol. 14, no. 8, 30 Aug. 2013, pp. 47954800, 10.7314/apjcp.2013.14.8.4795. Accessed 8 Nov. 2019.

Kelly, N. An Exploration into the Motivations, Barriers, and Benefits Associated with Volunteering among Final Year Full-Time Undergraduate Students. 2014, bitstream. Accessed 11 Nov. 2020.

Laville, S. "Single-Use Plastics a Serious Climate Change Hazard, Study Warns." The Guardian, The Guardian, 16 May 2019, www.theguardian.com/environment/2019/may/15/single-useplastics-a-serious-climate-change-hazard-study-warns. Accessed 11 Nov. 2020.

Liarakou, G, et al. "Environmental Volunteers: Factors Influencing Their Involvement in Environmental Action." Environmental Education Research, vol. 17, no. 5, Oct. 2011, pp. 651-673, 10.1080/13504622.2011.572159. Accessed 14 Oct. 2019.

Lindsay, L. Family Volunteering in Environmental Stewardship Initiatives (Pp. 1-24). Toronto. 2006, www.imaginecanada.ca/files/www/en/library/kdccdc/evergreen_family_volunteering.pdf.

Low, N, et al. Helping Out : A National Survey of Volunteering and Charitable Giving. London, London: Cabinet Office, 2007.

MacNeela, P. "The Give and Take of Volunteering: Motives, Benefits, and Personal Connections among Irish Volunteers." VOLUNTAS: International Journal of Voluntary and Nonprofit Organizations, vol. 19, no. 2, 25 Apr. 2008, pp. 125-139, 10.1007/s11266-008-9058-8. Accessed 11 Mar. 2019.

Marta, E, and M Pozzi. "Young People and Volunteerism: A Model of Sustained Volunteerism during the Transition to Adulthood." Journal of Adult Development, vol. 15, no. 1, 23 Jan. 2008, pp. 35-46, 10.1007/s10804-007-9033-4. Accessed 14 Oct. 2019.

Measham, T G, and G B Barnett. "Environmental Volunteering: Motivations, Modes and Outcomes." Australian Geographer, vol. 39, no. 4, Dec. 2008, pp. 537-552, 10.1080/00049180802419237. Accessed 13 Dec. 2019.

Moffatt, L. Engaging Young People in Volunteering: What Works in Tasmania?. Volunteering Tasmania, 2011, www.volunteeringtas.org.au/wp-content/uploads/2016/04/Engaging-YoungPeople-Report-Executive-Summary.pdf.

Mowen, J C, and H Sujan. "Volunteer Behavior: A Hierarchical Model Approach for Investigating Its Trait and Functional Motive Antecedents." Journal of Consumer Psychology, vol. 15, no. 2, Jan. 2005, pp. 170-182, 10.1207/s15327663jcp1502_9.

Narksompong, J, and S Limjirakan. "Youth Participation in Climate Change for Sustainable Engagement." Review of European, Comparative \& International Environmental Law, vol. 24, no. 2, July 2015, pp. 171-181, 10.1111/reel.12121. Accessed 12 Mar. 2020.

O.Nyumba, T, et al. "The Use of Focus Group Discussion Methodology: Insights from Two Decades of Application in Conservation." Methods in Ecology and Evolution, vol. 9, no. 1, Jan. 2018, pp. 20-32, besjournals.onlinelibrary.wiley.com/doi/full/10.1111/2041-210X.12860, 10.1111/2041-210x.12860. 
Ott, J S, and L A Dicke. The Nature of the Nonprofit Sector. Boulder: Westview Press, 2016.

Puckett, G N. Exploring Youth Engagement in Environmental Volunteering: Findings from a Cross-Case Analysis.

2015, prism.ucalgary.ca/bitstream/handle/11023/2130/ucalgary_2015_Puckett_Grace.pdf?sequence=4 \&isAllowed=y.

Quiroz-Martinez, J, et al. ReGeneration: Young People Shaping Environmental Justice. Oakland, Calif., Movement Strategy Center, 2005.

Raba'ah Hamzah, S, et al. "Understanding the Reasons for Malaysian Youth Participation in Volunteering Activities." Athens Journal Of Social Sciences, vol. 3, no. 1, 31 Dec. 2015, pp. 39-52, 10.30958/ajss.3-1-4. Accessed 11 Nov. 2020.

Rovers, J, et al. "Motivations, Barriers and Ethical Understandings of Healthcare Student Volunteers on a Medical Service Trip: A Mixed Methods Study." BMC Medical Education, vol. 16, no. 1, 22 Mar. 2016, www.ncbi.nlm.nih.gov/pmc/articles/PMC4845470/, 10.1186/s12909-016-06180 . Accessed 5 Jan. 2020.

Sahri, M, et al. "Empowering Youth Volunteerism: The Importance and Global Motivating Factors." Journal of Educational and Social Research, vol. 3, no. 7, 1 Jan. 2013, 10.5901/jesr.2013.v3n7p502. Accessed 5 June 2019.

Shannon, C S, et al. "Understanding Constraints Younger Youth Face in Engaging as Volunteers." Shannon, C.S., Robertson, B., Morrison, K., \& Werner, T.L. (2009). Understanding Constraints Younger Youth Face in Engaging as Volunteers. Journal of Park and Recreation Administration, 27., vol. 27, no. 4, 2009, js.sagamorepub.com/jpra/article/view/1270.

Smith, K, et al. "Motivations and Benefits of Student Volunteering: Comparing Regular, Occasional, and Non-Volunteers in Five Countries." Canadian Journal of Nonprofit and Social Economy Research, vol. 1, no. 1, 26 Oct. 2010, repository.upenn.edu/cgi/viewcontent.cgi?article=1165\&context=spp_papers, 10.22230/cjnser.2010v1n1a2. Accessed 4 Mar. 2019.

Squirrell, G. Student Volunteering: Background, Policy and Context for NCCPE Student Volunteering. Bristol: NCCPE, 2009.

Suandi, T, et al. "Knowledge, Attitude and Spirit of Volunteerism among Students in Public Institution of Higher Learning." International Conference on Youth Development 2011, 2011, www.researchgate.net/publication/260714601_Knowledge_Attitude_and_Spirit_of_Volunteerism _among_Students_in_Public_Institution_of_Higher_Learning.

Tessier, S, et al. "Youth Volunteerism Research Report." Sector Source, 2006, sectorsource.ca/sites/default/files/resources/files/laval_youthstudy_report.pdf.

UN World Youth Report. Chapter 5: Youth and the EnvironmentUnited Nations. United Nations, 2003.

Volunteer Canada. Volunteer Connections : New Strategies for Involving Youth. Volunteer Canada, 2001, volunteer.ca/files/NewstratEng.pdf.

Wilson, J. “Volunteering.” Annual Review of Sociology, vol. 26, no. 1, Aug. 2000, pp. 215-240, www.deepdyve.com/lp/annual-reviews/volunteering-0sIzvtdIb8, 10.1146/annurev.soc.26.1.215. 